\title{
Interactive comment on "Tectonothermal evolution in the core of an arcuate fold and thrust belt: the southeastern sector of the Cantabrian Zone (Variscan belt, NW Spain)" by M. L. Valín et al.
}

\author{
T Blenkinsop (Referee) \\ blenkinsopt@cardiff.ac.uk \\ Received and published: 13 May 2016
}

This paper is a well-written and illustrated detailed study of low grade metamorphism in the core of the Cantabrian Zone. The results from almost 300 samples over a vast area are presented, which is a very impressive database to work from. XRD was used to determine phyllosilicate mineralogy, Kübler Index (KI) of illites, and Árkai Index of chlorites (Al).

Unsurprisingly, given such a large database and study area, the metamorphic indices and mineralogy are very complex, and the paper wisely does not over-interpret them. The main results are that there are two tectonothermal events, and that some of the highest temperatures are localised around intrusions. 
The existence of two tectonothermal events is significant, but not well documented: there are simply two field photographs of the fabrics, from different outcrops, since they do not occur together. It is a pity that there is not a more detailed structural analysis to back this up, especially as the paper is titled "Tectonothermal evolution in the core of an arcuate fold and thrust belt: the southeastern sector of the Cantabrian Zone (Variscan belt, NW Spain)". The thermal part is well covered, but not the tectonic part.

Interactive

comment

The intrusions and related tectonothermal event are quite intriguing. Given the lack of syntectonic intrusions to the west of the study area in the Cantabrian zone, it is quite surprising to read about them here, and about an extensional event that is apparently not manifested to the west. It would make a really great addition to this paper if the geodynamics of this event could be explained in a broader context.

The statement that metamorphic indices do not correlate with stratigraphy is made quite strongly. This is an important point, so a revision of this paper would preferably include a figure with averages and ranges for the major stratigraphic units.

Detailed comments

Page 3, Line $97 \mathrm{ff}$. It would be good to state the age of these intrusions here. Page 4. Was conventional chlorite geothermometry considered as a method? The results in this paper are all based on XRD, so an alternative would be a useful check. Page 8, line 272. Replace "big size" by a dimension. Page 10, Line $365 \mathrm{ff}$. What does geophysics say about the likely sub-surface configuration of these intrusions? Could they have supplied the necessary heat?

Figures. The maps are very detailed and impressive, although it is difficult to see any broader patterns because of the detail, except for Fig. 8. One query is why the areas of igneous rocks on Fig. 6 are much larger than on the other figures.

Interactive comment on Solid Earth Discuss., doi:10.5194/se-2016-53, 2016. 